\title{
Competitive Effects Hinder the Recolonization of Native Species in Environments Densely Occupied by One Invasive Exotic Species
}

\section{OPEN ACCESS}

Edited by:

Rossano Bolpagni,

Istituto per il Rilevamento

Elettromagnetico dell'ambiente

(IREA), Italy

Reviewed by:

llias Travlos,

Agricultural University of Athens,

Greece

Daniele Longhi,

Università degli Studi di Parma, Italy

*Correspondence:

Thaisa S. Michelan

tsmichelan@ufpa.br

Specialty section:

This article was submitted to

Functional Plant Ecology,

a section of the journal

Frontiers in Plant Science

Received: 05 August 2017

Accepted: 10 August 2018

Published: 04 September 2018

Citation:

Michelan TS, Thomaz SM, Bando FM and Bini LM (2018) Competitive Effects Hinder the Recolonization of Native Species in Environments Densely Occupied by One Invasive Exotic Species.

Front. Plant Sci. 9:1261. doi: 10.3389/fpls.2018.01261

\section{Thaisa S. Michelan ${ }^{1,2 *}$, Sidinei M. Thomaz ${ }^{1}$, Fabielle M. Bando ${ }^{1}$ and Luis M. Bini ${ }^{3}$ \\ ${ }^{1}$ Departamento de Biologia, Universidade Estadual de Maringá, Nupelia, Maringá, Brazil, ${ }^{2}$ Laboratório de Ecologia e Conservação, Instituto de Ciências Biológicas, Universidade Federal do Pará, Belém, Brazil, ${ }^{3}$ Departamento de Ecologia, Instituto de Ciências Biológicas, Universidade Federal de Goiás, Goiânia, Brazil}

The responses of native plants to competition with invasive plants depend mainly on the density of the invasive plants and on the ability of the native plants to compete for resources. In this study, we tested the influence of the invasive exotic Urochloa arrecta (Poaceae) on the early colonization of two native species (Pontederia cordata and Leersia hexandra) of aquatic macrophytes. Our hypotheses were (i) the competitive effects of $U$. arrecta on the native species $P$. cordata and $L$. hexandra are densitydependent and that (ii) these species respond differently to competitive interactions with the invasive species. We conducted the experiments in a greenhouse and in the field, in a tropical reservoir. The biomass of $U$. arrecta (ranging from 206.2 to $447.1 \mathrm{~g}$ ) was manipulated in the greenhouse in trays with different densities. After the establishment of the invasive species, we added $P$. cordata and $L$. hexandra propagules to each tray. In the field, a propagule of $P$. cordata was planted in 36 sites with different densities of $U$. arrecta. The biomass and length of the natives and the biomass of the invasive species were measured in the greenhouse and in the field experiments. The biomass and length of the native plants decreased with increasing biomass of the exotic species in both experiments, showing that the competition between $U$. arrecta and native species depends on the density of the exotic species. The root:shoot ratio of $L$. hexandra decreased with increasing $U$. arrecta biomass, but the opposite occurred for $P$. cordata. These results indicate that native species exhibit different strategies of biomass allocation when interacting with $U$. arrecta. The strong competitive effects of $U$. arrecta and the different responses of the native species help to explain the reduced diversity of native macrophytes observed in sites colonized by $U$. arrecta. The results also suggest that in a scenario of dominance of exotic species, recolonization by native macrophytes is unlike to occur naturally and without human interventions that reduce the biomass of the exotic species.

Keywords: competition, non-native macrophytes, Poaceae, density-dependent effect, resource competition 


\section{INTRODUCTION}

In general, only a small fraction of introduced species become successfully established and exhibit population growth to the point of becoming "invasive" (Levine, 2008; Davis, 2009). When they do become invasive, they can reduce the richness and abundance of native species (Madsen et al., 1991; Daehler and Strong, 1994; Roberts et al., 1999; Michelan et al., 2010b). In addition, they can even change the environmental conditions of the invaded sites (Pyšek et al., 2008; Strayer, 2010), causing ecological and economic damage (Richardson and Pyšek, 2008; Carey et al., 2016; Cuassolo et al., 2016). Invasion success depends on multiple factors, including species-specific traits (e.g., growth rate, competitiveness and dispersal ability; Rejmánek, 2011) and the characteristics of the invaded ecosystem (e.g., environmental conditions, disturbances and diversity; Fridley, 2011).

The impacts of invasive species on native species depend largely on the abilities of interacting species to compete for resources (Seabloom et al., 2003; Blindow et al., 2016). Competition is an important biological interaction that influences the structure and development of plant communities (Kiaer et al., 2013; Blindow et al., 2016). Additionally, species respond differently to competition depending on the abiotic conditions and on the density of each population (Gopal and Goel, 1993; Nunes and Camargo, 2017). As a direct result of competition with invasive species, one can predict changes in the structure of invaded communities and a decrease in biodiversity at local and regional scales (Michelan et al., 2010b; Powell et al., 2011, 2013; Amorim et al., 2015).

Competition among plants occurs predominantly by nutrient ("root competition") and/or light acquisition ("above-ground competition"). The roots and shoots of the plants acquire different resources from the environment, and some studies therefore try to separate the effects of the competition of each plant part (Wang et al., 2008; Kiaer et al., 2013; Richter and Gross, 2013). One of the methods to evaluate which organ is most involved in the competition is to use root:shoot biomass ratio (Robinson et al., 2010). High values of this ratio indicate that competition for nutrients and water (by root) is more important, while lower values indicate greater competition for light (Wang et al., 2008; Craine and Dybzinski, 2013; Kiaer et al., 2013; Richter and Gross, 2013; but see Cahill, 2003 for another point of view).

Coexistence between species under natural conditions can be facilitated by several mechanisms, such as disturbances and trade-offs between competitive and dispersal abilities (Grime, 1979; Connell, 1983). However, the competitive effects of invasive species occurring at high densities may be so intense that, at least at fine spatial scales, native species are excluded by competition (Madsen et al., 1991). Yet, little is known about the tolerable limits of the biomass of invasive macrophytes for the recolonization of native macrophyte species. Thus, it is important to evaluate the competitive interactions between native and invasive macrophyte species at different biomasses of the latter. Studies employing this approach would help to identify native species with higher potential for recolonizing environments dominated by invasive species and to identify thresholds of invasive biomass that allow native recolonization and survival.
Many species belonging to the family Poaceae are highly invasive in several aquatic ecosystems (Bunn et al., 1998; Bell et al., 2011; Mugwedi et al., 2015). In general, they have greater competitive effects than species of other groups, such as herbaceous and leguminous plants (Kiaer et al., 2013). This is also the case for Urochloa arrecta (Hack. ex T. Durand \& Schinz) Morrone \& Zuloaga, a species native to Africa, which has colonized tropical and subtropical aquatic ecosystems. In particular, this species is invading and causing ecological impacts in various Brazilian aquatic ecosystems (Pott et al., 2011; Fernandes et al., 2013; Amorim et al., 2015). U. arrecta forms large patches, accumulates large amounts of biomass in littoral zones (Michelan et al., 2010b; Fernandes et al., 2013; Amorim et al., 2015), regenerates rapidly after disturbances (Michelan et al., 2010a) and can thrive even in relatively oligotrophic environments with nutrient-poor sandy substrates (Fasoli et al., 2015). However, there is a paucity of experimental studies evaluating the competitive effects of $U$. arrecta on individual macrophyte species.

In this study, we investigated the biomass-dependent effects of $U$. arrecta on the recolonization of two native species of macrophytes (Pontederia cordata L. and Leersia hexandra Sw.) and tested whether the competitive effects on them differ. First, we developed a greenhouse experiment to test the effects of $U$. arrecta on the biomass and on the root:shoot ratio of the two native species. Then, we repeated the experiment in the field, using $P$. cordata as a focal species, to test the generality of our results obtained in the greenhouse. We tested the hypotheses that (i) the competitive effects of $U$. arrecta on $P$. cordata and $L$. hexandra depend on the invasive biomass and (ii) that native species respond differently to these effects. These hypotheses were postulated because previous studies in the field showed that the native macrophyte biomass decreases in the presence of $U$. arrecta (Michelan et al., 2010b) and that the frequencies of co-occurrence between native macrophytes and $U$. arrecta are species-specific, indicating that native species may respond differently to increasing invasive biomass (Thomaz and Michelan, 2011). We predicted that the effects of $U$. arrecta on $L$. hexandra would be higher than those on $P$. cordata because of the morphological similarity and phylogenetic relationship between the first pair of species. Consequently, they should use resources more similarly, which intensifies competition and reduces the chances of co-existence (Chesson and Kuang, 2008; Rejmánek, 2011). Finally, to place our results in a broader context, we compared our results with those obtained in a recent meta-analysis (Jauni and Ramula, 2015).

We believe that the use of $U$. arrecta as a model plant in our study contributes to a broader view regarding the impacts of exotic plants on native species because this species belongs to the family Poaceae, which is responsible for the greatest ecological impacts among invasive plants (Kiaer et al., 2013). In addition, by conducting experiments in a greenhouse and in the field, we believe that our outcomes can be useful to assess whether the former can be extrapolated to nature, an issue that has been questioned by some investigations that highlight the shortcomings of microcosm experiments (e.g., Wilson and Keddy, 1991). 


\section{MATERIALS AND METHODS}

We performed two experiments employing an additive design (Gibson et al., 1999) to assess the ability of native species to colonize and grow in sites with different biomasses of $U$. arrecta, one experiment in a greenhouse at the State University of Maringá (Paraná State, Brazil) and the other in situ in the Rosana Reservoir (Paraná/São Paulo, Brazil; 22 $2^{\circ} 39^{\prime} 26.19^{\prime \prime}$ S 52 46 $52.35^{\prime \prime}$ W; see Supplementary Figure $\mathbf{S 1}$ for photos of the experiment in a greenhouse and in situ).

\section{Greenhouse Experiment}

Urochloa arrecta (exotic), P. cordata, and L. hexandra (natives) were used in our greenhouse experiment. The native species were selected based on different levels of co-occurrence with $U$. arrecta (details about this selection in Michelan et al., 2013). L. hexandra (Poaceae species often found to co-occur with $U$. arrecta) is a perennial species that can grow vigorously in aquatic ecosystems (Pott and Pott, 2000; Moreira et al., 2011). The Pontederiaceae $P$. cordata has low level of co-occurrence with $U$. arrecta and is a perennial herbaceous species that can also form dense stands (Pott and Pott, 2000). Both species reproduce sexually and asexually (by stems and rhizomes). P. cordata rhizomes can survive to fire or dry seasons (Pott and Pott, 2000). The macrophytes were collected in the Rosana Reservoir and taken to the greenhouse.

We used trays $(0.30 \mathrm{~m} \times 0.37 \mathrm{~m} \times 0.14 \times \mathrm{m})$ that were filled halfway with sediment and maintained with a $3-5 \mathrm{~cm}$ water layer. The water was replaced with tap water whenever necessary. To create a gradient of $U$. arrecta biomass, we added fragments with two nodes each of $U$. arrecta from the apical stems, at densities of $0,5,10,15,20,25$, and 30 fragments per tray, with five replicates for each treatment, amounting to 35 trays. Trays were randomized inside the greenhouse to offset any undetected environmental variation.

A clear gradient in biomass, a necessary condition to test our hypotheses, was formed by 200 days after planting U. arrecta $\left(0-450 \mathrm{~g} \mathrm{DW} \mathrm{m}^{-2}\right)$. Then, we added one propagule of $P$. cordata and one of $L$. hexandra at the opposite extremes of each tray (separated from each other by ca. $30 \mathrm{~cm}$ ). These propagules of $P$. cordata and $L$. hexandra were collected in the Rosana Reservoir and brought to the greenhouse, where we removed their leaves and roots in order to allow all plants to start to grow at similar conditions. In addition, we selected propagules with similar weights. The distance between the native species in the microcosms (ca. $30 \mathrm{~cm}$ ) was assumed to be enough to avoid interaction between them. Although we did not measure the survival rates of the propagules of the native species during the course of the experiment, all propagules survived in our experiment and even those planted in more dense microcosms formed small individuals.

The experiment was completed 3 months after the introduction of the native species. The length of $P$. cordata and the average length of shoots generated by $L$. hexandra were measured with a tape $(\mathrm{cm})$. Afterward, the biomass of each species was washed to remove sediment and was separated into shoots and roots. After drying in an oven $\left(70^{\circ} \mathrm{C}\right.$, until constant weight), the dry mass of roots and shoots of each species was measured on a scale with a precision of $0.01 \mathrm{~g}$. We emphasize that the experimental design of this study simulates a situation in which the recolonization by native aquatic macrophyte species occurs after the occupation of an invasive exotic species that is dominant in an ecosystem, a common situation in several Neotropical aquatic environments.

\section{Field Experiment}

The field experiment was conducted in one arm of the

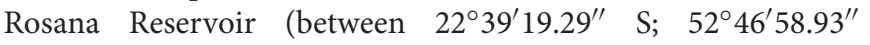
$\mathrm{W}-22^{\circ} 40^{\prime} 27.19^{\prime \prime} \mathrm{S} ; 52^{\circ} 47^{\prime} 10.32^{\prime \prime} \mathrm{W}$ and $22^{\circ} 39^{\prime} 32.42^{\prime \prime} \mathrm{S}$; $52^{\circ} 46^{\prime} 36.52^{\prime \prime} \mathrm{W}-22^{\circ} 40^{\prime} 26.18^{\prime \prime} \mathrm{S}$; $52^{\circ} 46^{\prime} 47.43^{\prime \prime} \mathrm{W}$; Brazil), near the sites where the native macrophytes were collected for the greenhouse experiment. We first selected 50 sites (squares of $0.09 \mathrm{~m}^{2}-0.3 \mathrm{~m} \times 0.3 \mathrm{~m}$ ) with different densities of $U$. arrecta. These sites were identified and demarcated with stakes, and a propagule of $P$. cordata was planted in each site. The P. cordata propagules were treated the same way as those used in the greenhouse (see details above for the greenhouse experiment). We monitored the field experiment at every week and observed that the propagules of $P$. cordata were consumed by herbivores in 14 sites. Thus, 3 months after the establishment of the native species, only 36 sites were used in this study.

At the end of the experiment (90 days), the individuals of P. cordata and the shoots of $U$. arrecta in an area of $0.09 \mathrm{~m}^{2}$ $(0.3 \mathrm{~m} \times 0.3 \mathrm{~m})$ around the native species were collected. For each site, the species were separated and washed, packed and placed in an oven at $70^{\circ} \mathrm{C}$ until reaching a constant weight. The dry shoot biomass of $U$. arrecta and the shoot and root biomass of $P$. cordata were obtained by using a precision scale with an accuracy of $0.01 \mathrm{~g}$.

\section{Data Analysis}

Following Goldberg and Scheiner (2001), we used an analysis of covariance (ANCOVA) for each response variable (i.e., total biomass, length and root:shoot ratio of native plants). In each ANCOVA model, the quantitative and categorical predictor variables were the shoot biomass of $U$. arrecta and the native species identity (L. hexandra and $P$. cordata), respectively. The response variables were standardized to the values of these variables expected in the absence of $U$. arrecta. Thus, we expressed them as $\log$ response ratios, $\ln R R=\ln \left(Y_{\mathrm{u}} / Y_{\mathrm{c}}\right)$, where $Y_{\mathcal{c}}$ was the value of a response variable without $U$. arrecta and $Y_{\mathrm{u}}$ was the value of this response variable under the influence of $U$. arrecta. To estimate $Y_{\mathfrak{c}}$, we used the mean values of the response variables in the control experimental units. Thus, $\ln R R$ is equal to 0.0 in the absence of competitive effects, and the more negative $\ln R R$ is, the higher the effect of $U$. arrecta in limiting the growth of the natives. As our objective was to analyze the competition between the invasive and native species and to evaluate whether they responded differently to the competition effect in a scenario of exotic dominance, we chose to remove the sites with the absence of the invasive species (but see the Supplementary Figure S2 for the results based on the entire gradient of $U$. arrecta biomass-with the addition of treatment 0 -absence of competition). 
In the field experiment, the effect of $U$. arrecta biomass on $P$. cordata biomass was tested using a second-order polynomial regression due to the non-linearity of the data. All statistical analyses were performed in R (R Development Core Team, 2014).

\section{Comparison of the Results With Those Obtained in the Literature}

To contrast our results with those obtained in the literature, we first transformed the Pearson correlation coefficient $(r)$ between the total biomass of the invasive species and the total biomass of the native species into Cohen's $d$ using: $d=2 r / \sqrt{1-r^{2}}$ (Borenstein et al., 2009). The variance of $d\left(V_{d}\right)$ is given by: $V_{d}=4 V_{r} /\left(1-r^{2}\right)^{3}$, where $V_{r}$ is the variance of $r$ $\left(V_{r}=\left(1-r^{2}\right)^{2} / n-1\right)$ and $n$ is the sample size. Finally, $d$ was transformed into Hedges' $g$ after multiplying $d$ by a correction factor $j$ (see Eq. 4.22 in Borenstein et al., 2009). The variance of $g$ was estimated by $V_{g}=j^{2} \times V_{d}$. Second, we compared the values of $g$ estimated in our study with the results of a recent meta-analysis conducted by Jauni and Ramula (2015). This meta-analysis was based on 75 competition studies between exotic and native species. These studies (observational and experimental) evaluated "how exotic plant species influence the fitness components of native plants" (Jauni and Ramula, 2015) and were based on the following response variables: establishment (i.e., germination), growth rate, biomass, reproductive success and survival (or mortality). Fifty-eight exotic species were included, and it is important to note that no study with $U$. arrecta was used in this meta-analysis, ensuring independent results. We focused our comparison on results obtained for biomass, based on studies with 19 exotic species (mainly from the order Poales) and 36 native species (see Figure 1 of Jauni and Ramula, 2015). In general, the approach of quantitatively comparing the results obtained in an experiment with those obtained in a meta-analysis can be considered a type of cumulative meta-analysis (Leimu and Koricheva, 2004).

\section{RESULTS}

\section{Greenhouse Experiment}

We found that the total biomass of both native species significantly decreased with the increase in the biomass of $U$. arrecta. The slopes of the relationships did not differ significantly (test of parallelism: $F_{1,56}=3.47 ; P=0.0676$; Figure 1A). However, the coefficient of determination of the model for L. hexandra $\left(R^{2}=0.70 ; P<0.001\right)$ was substantially higher than that observed for $P$. cordata $\left(R^{2}=0.51 ; P<0.001\right)$.

Similar to what we found for biomass, the native species' length decreased significantly with the increase in the biomass of $U$. arrecta (Figure 1B). However, the slope of the relationship between the biomass of $U$. arrecta and length of $L$. hexandra $\left(b=-0.0032 \pm 0.0006 \mathrm{SE} ; R^{2}=0.54 ; P<0.001\right)$ was significantly steeper (test of parallelism: $F_{1,56}=5.14 ; P=0.0272$ ) than that for $P$. cordata $\left(b=-0.0017 \pm 0.0003 \mathrm{SE} ; R^{2}=0.48 ; P<0.001\right)$.

The effects of the $U$. arrecta biomass on the root:shoot ratio clearly differed between the two native species $\left(F_{1,56}=60.58\right.$;
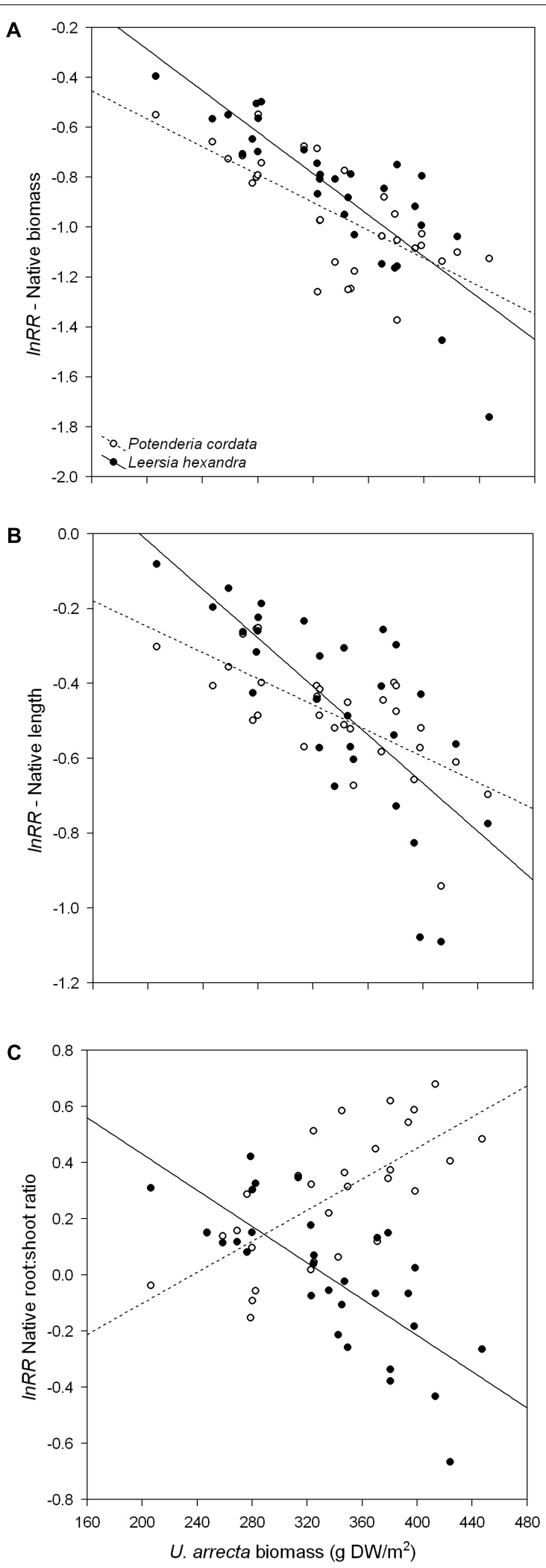

FIGURE 1 | Relationship between the shoot biomass of $U$. arrecta and different traits of two species of native macrophytes. Shown are the results for (A) total biomass, (B) length, and (C) root:shoot ratio. 
$P<0.001$; Figure 1C), being positive for $P$. cordata $\left(b=0.0028 \pm 0.0005 \mathrm{SE} ; R^{2}=0.49 ; P<0.001\right)$ and negative for L. hexandra $\left(b=-0.0032 \pm 0.0006 \mathrm{SE} ; R^{2}=0.54 ; P<0.001\right)$. Despite the opposite effects, the magnitudes of the slopes were similar. These results indicate that $L$. hexandra invests more in shoots, while $P$. cordata invests more in belowground structures (roots), with an increasing degree of competition with $U$. arrecta.

\section{Field Experiment}

The results obtained in the field experiment with $P$. cordata followed the pattern found in the greenhouse. The biomass of $U$. arrecta negatively affected the biomass of $P$. cordata $\left(b=-0.0472 \pm 0.006 \mathrm{SE} ; R^{2}=0.85 ; P<0.001\right.$; Figure 2A). The root:shoot ratio of the biomass of this native species was positively and significantly affected by the biomass of the invasive species $\left(b=0.003 \pm 0.0001 \mathrm{SE} ; R^{2}=0.76 ; P<0.001\right.$; Figure 2B).

\section{Comparison of the Results With Those Obtained in the Literature}

The effect of $U$. arrecta on native species was substantially larger than the effects reported in the meta-analysis of Jauni and Ramula (2015). The results of this comparison also indicate that the negative effect of $U$. arrecta on $L$. hexandra was greater than that estimated for P. cordata in the greenhouse experiment. However, the largest effect size was estimated for $P$. cordata when the experiment was carried out in the field, despite the high overlap between the confidence intervals (Figure 3).

\section{DISCUSSION}

We found that the competitive effects of $U$. arrecta on P. cordata and $L$. hexandra are biomass-dependent, corroborating our first hypothesis. Most importantly, in accordance with our second hypothesis, we showed that the native species responded differently to the competitive interaction with the invader, at least in terms of plant height and root:shoot ratios. In addition, it is likely that the increase in $U$. arrecta biomass increases the competition for nutrient acquisition more in $P$. cordata than in $L$. hexandra, given that the former species invested more in root growth when in greater competitive interaction with $U$. arrecta than the latter. However, although these native species responded differently to the competitive interaction with the invader, $L$. hexandra was not the most negatively affected by $U$. arrecta (as suggested by similar responses in terms of biomass production), which contradicts our prediction in this regard.

The negative effects of $U$. arrecta on native species were even stronger in the field experiment, where the growth of $P$. cordata was nearly suppressed at high densities of $U$. arrecta (see Figure 2A). These results, along with those obtained in the greenhouse, indicate that high densities of the invasive species decrease recolonization success by native species, which may explain the pattern of reduced macrophyte diversity with the increase of $U$. arrecta biomass at small spatial scales (Michelan et al., 2010b; Amorim et al., 2015). Our findings agree with studies carried out with other invasive species that showed the importance of density in the establishment success of native species, mainly in controlled experiments (Doyle et al., 2003; Martin and Coetzee, 2014). Thus, in field conditions, the effects of exotic species on the growth of native species are likely to be much stronger than the effects measured in greenhouse experiments. For example, the biomass that $U$. arrecta may attain in the field (approx. $7000 \mathrm{~g} \mathrm{DW} \mathrm{m}^{-2}$; Carniatto et al., 2013) is much higher than the highest biomass in our experiment (approx. $2000 \mathrm{~g} \mathrm{DW} \mathrm{m}^{-2}$ ).

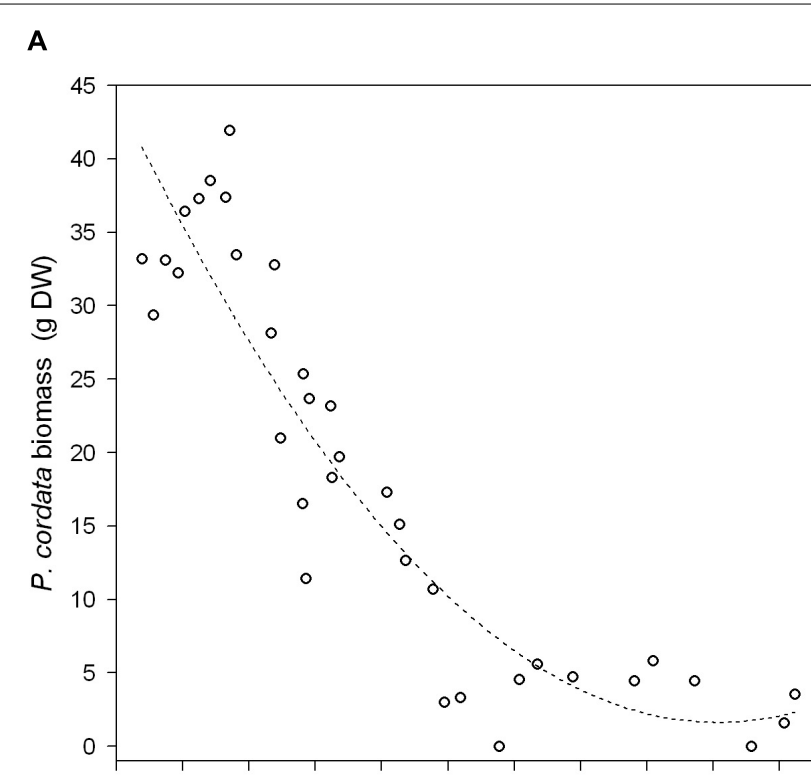

B

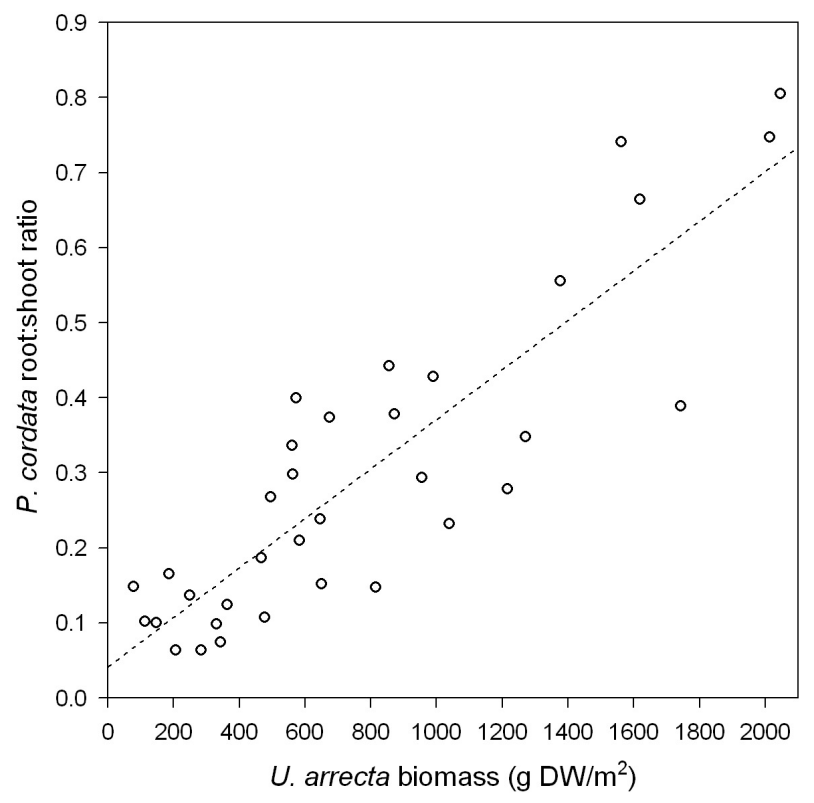

FIGURE 2 | Relationship between the shoot biomass of $U$. arrecta and the biomass (A) and root:shoot ratio (B) of Pontederia cordata (data from the in situ experiment). 


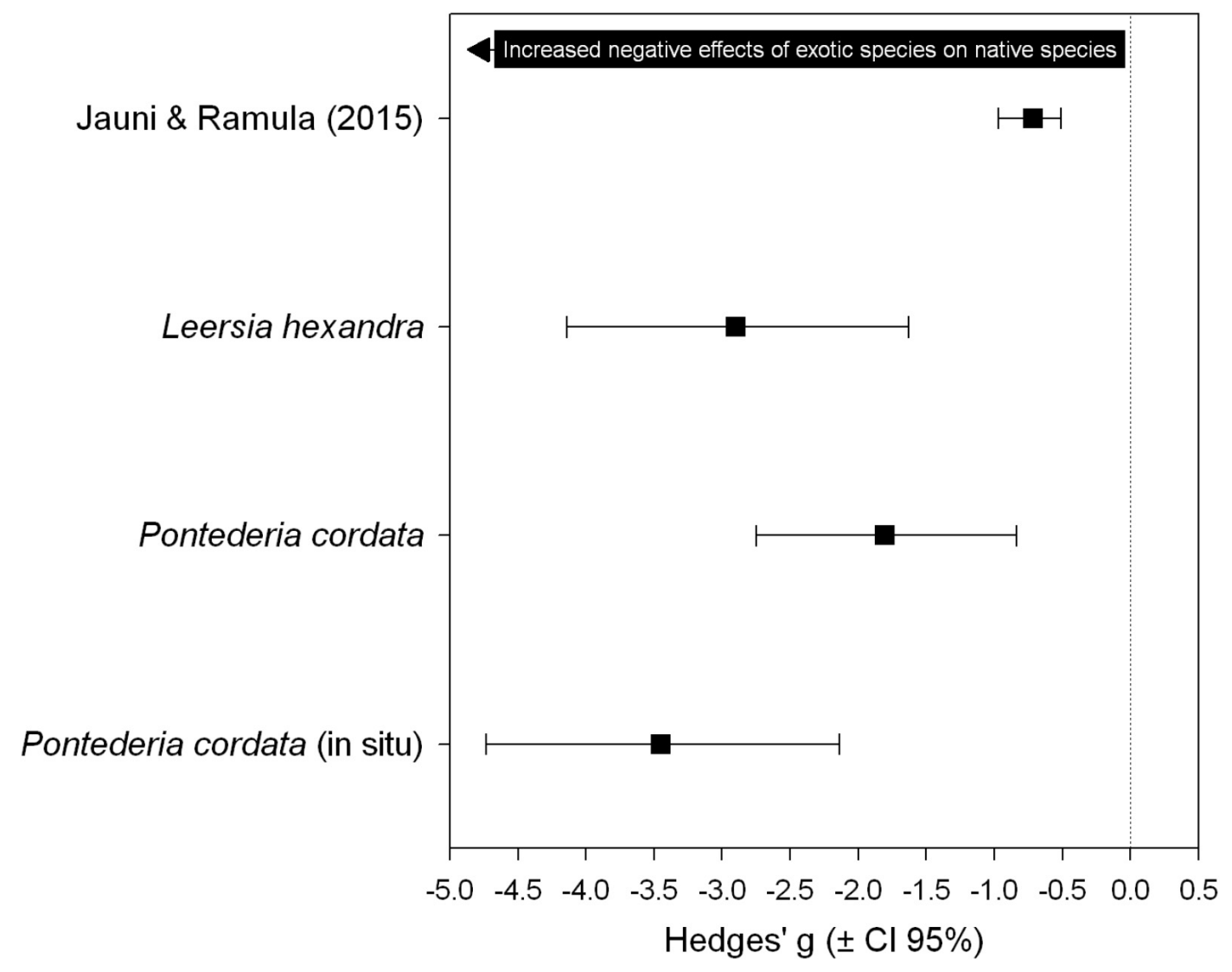

FIGURE 3 | Cumulative effect size estimated by Jauni and Ramula (2015) and effect sizes estimated in this study. These assess the effects of invasive exotic plants on the biomass of native plants.

Macrophytes respond to competition (Burns and Winn, 2006) and other environmental factors, such as increase in water level (Gomaa and AbdElgawad, 2012), by shoot elongation. The elongation (or etiolation) of terrestrial and aquatic plants is, in general, a response to light limitation (e.g., Goldsborough and Kemp, 1988; Paciullo et al., 2008, 2011; Li et al., 2011). However, our results indicate a reduction in the length of native species with increased competition (and shading) by $U$. arrecta (see Figure 1B). Thus, our results agree with other studies showing that not all species are able to etiolate in the face of light competition. For example, Burns and Winn (2006) demonstrated that competition reduced the lengths of two grass species. A plausible explanation for the lack of etiolation in face of competition, applicable only to $L$. hexandra, is that the light limitation was offset by the increased investment in the biomass of the shoots, as shown by the results for the root:shoot ratio (see below). By contrast, $P$. cordata has broader leaves than $L$. hexandra, and thus, increased light acquisition may be obtained by increases in leaf area instead of etiolation. These factors may also explain the steeper reduction in length for $L$. hexandra than for $P$. cordata along the invasive biomass gradient.

The native species responded differently to the increase in $U$. arrecta biomass in terms of investment in belowground or aboveground structures (see Figure 1C), revealing different strategies to overcome competition with the invasive species. The increase in plant density exacerbates competition, which may occur for space, nutrients and/or light (Witkowski, 1991; Daehler, 2003; Doyle et al., 2003; Davis, 2009). Increased investment in shoots indicates a predominance of competition between aboveground plant structures, while high investment in roots indicates dominance of competition between belowground structures (e.g., Berendse and Möller, 2009; Janeček et al., 2014). Based on this premise, our results indicate that L. hexandra growth becomes increasingly limited by light availability over a gradient of $U$. arrecta biomass, while $P$. cordata growth becomes increasingly limited by nutrients and space over the same biomass gradient. The largest investment in shoots by $L$. hexandra at high densities of the invasive probably occurs because Poaceae are, in general, highly sensitive to shading conditions. Allocation to shoot biomass, relative to root biomass, is likely to be a response to light limitation under high competition, as observed for other herbaceous species (Gibson et al., 2004; Awan et al., 2015). On the other hand, increased allocation to roots in P. cordata indicates a response to root competition (for other examples, see Bakker and Wilson, 2001; Schiffers et al., 2011; Zhu et al., 2015).

Despite the changes in biomass allocation of the native species over the competition gradient, there was a reduction 
of approximately $90 \%$ of the native species biomass at high biomass of $U$. arrecta, and the reduction was even higher for $P$. cordata in the field. The significant reduction in the growth of native species when exotic species are dominant, as simulated in our experiments, supports the model of preemptive competition, as found in other studies (Grace, 1987; Seabloom and van der Valk, 2003; Moore and Franklin, 2012; Moore et al., 2014). In practical terms, our experimental results indicate that native species have low capacities to recolonize sites dominated by invasive species. In addition, along with results of "invasiveness" experiments (e.g., Xu et al., 2004; Michelan et al., 2013), our results suggest that pre-occupation is key to predicting competition effects. The negative effects on the native species derived from the pre-occupation of the exotic species are likely to be more pronounced in ecosystems subject to anthropogenic impacts, since anthropogenic impacts are more favorable to the success of invasive plants (Daehler, 2003; Havel et al., 2005; Engelhardt, 2011). In summary, we speculate that the natural recolonization by native species in environments dominated by $U$. arrecta is unlikely and that their success can only occur if the invasive species is manipulated, reducing its occupation.

Experiments in greenhouses and controlled conditions are criticized for using small spatial and temporal scales and for not replicating the complexity found in natural environments (Gibson et al., 1999). Experiments like ours could, for example, bias the effects of shoot competition because of limited soil volume, which reduces shoot growth, and because of edge effects, which allow more access to light than would occur in the field (Kiaer et al., 2013). However, the data obtained in the field for $P$. cordata demonstrate that at least the direction and intensity of the competitive effects exerted by $U$. arrecta were similar to those found in the greenhouse. This congruence suggests that the data obtained experimentally in the greenhouse can be extrapolated to field situations, as the results obtained in the latter also indicate the importance of density-dependent effects of an invasive species on native species.

Finally, we believe that the larger effect sizes in our experiment compared to those estimated by Jauni and Ramula (2015) may indicate that $U$. arrecta possesses higher competitive effects than other invasive species. The consistent negative effect of exotic plants on the biomass of native plants, according to Jauni and Ramula (2015), may be explained by considering three mechanisms that are not mutually exclusive. The first mechanism, and probably the most important, is related to competition for light and nutrients, which reduces biomass and may cause a decrease in the reproductive success and survival of native plant species, leading to population decline (Jauni and Ramula, 2015). The other two mechanisms are related to pollinators and survival of recruits, but these mechanisms cannot be used to explain our results because our experiments considered only one plant generation. Interestingly, the results obtained by Jauni and Ramula (2015) suggest that native plants can be established when associated with exotic plants. These authors suggest that the population dynamics of native plants may not be limited by the availability of micro-sites but by competition with exotic species in later stages of the life cycle. Our results corroborate this expectation, since most of the native propagules established even in high biomass of the exotic species, but they attained extremely low growth and did not flower in this condition.

In short, our hypotheses that the effects of competition between $U$. arrecta and native macrophytes are density dependent and that $P$. cordata and $L$. hexandra respond differently to this competitive interaction were corroborated. Our results suggest that in a scenario of dominance of invasive Poaceae, recolonization by native macrophytes is unlike to occur naturally. Our results also indicate that the reduction of the diversity of native macrophytes observed in sites colonized by $U$. arrecta can be explained by the competitive effects of this invasive species. In practical terms, due to the density-dependent competitive effects, when it is not possible to eliminate the invasive species, a strategy to maintain it at low density would be required to allow recolonization by natives and to maintain local biodiversity. Also in this context, we believe that increasing the number of propagules to analyze the capacity of native species to recolonize environments densely colonized by exotic species would be an interesting avenue for further research.

\section{AUTHOR CONTRIBUTIONS}

TM and ST conceived the ideas and designed the experiments. TM, ST, and FB conducted the greenhouse and field experiments. TM and LB analyzed and interpreted the data. TM led the writing of the manuscript. ST and LB gave major input into the first draft. All authors contributed critically to the final version of the manuscript and approved it for publication.

\section{FUNDING}

We acknowledge the National Council for Scientific and Technological Development (CNPq) for providing a scholarship to $\mathrm{TM}$ and $\mathrm{FB}$, and for providing continuous funding to ST and LB through Productivity Grants. This study was also supported by the Brazilian Coordination for the Improvement of Higher Education Personnel (CAPES). This work was also developed in the context of the National Institutes for Science and Technology (INCT) in Ecology, Evolution and Biodiversity Conservation, supported by MCTIC/CNPq (proc. 465610/2014-5) and FAPEG.

\section{ACKNOWLEDGMENTS}

We thank M.C. Teixeira for helping with the greenhouse experiment.

\section{SUPPLEMENTARY MATERIAL}

The Supplementary Material for this article can be found online at: https://www.frontiersin.org/articles/10.3389/fpls.2018.01261/ full\#supplementary-material 


\section{REFERENCES}

Amorim, S. R., Umetsu, C. A., and Camargo, A. F. M. (2015). Effects of a nonnative species of Poaceae on aquatic macrophyte community composition: a comparison with a native species. J. Aquat. Plant Manag. 53, 191-196.

Awan, T. H., Sta Cruz, P. C., and Chauhan, B. S. (2015). Ecological significance of rice (Oryza sativa) planting density and nitrogen rates in managing the growth and competitive ability of itchgrass (Rottboellia cochinchinensis) in direct-seeded rice systems. J. Pest. Sci. 88, 427-438. doi: 10.1007/s10340-0140604-4

Bakker, J., and Wilson, S. (2001). Competitive abilities of introduced and native grasses. Plant Ecol. 157, 117-125. doi: 10.1023/A:1013972403293

Bell, K. L., Heard, T. A., and Van Klinken, R. D. (2011). Natural enemies of invasive Hymenachne amplexicaulis and its native congener in Australia and the potential for biological control. Biol. Control 57, 130-137. doi: 10.1016/j. biocontrol.2011.01.009

Berendse, F., and Möller, F. (2009). Effects of competition on root-shoot allocation in Plantago lanceolata L.: adaptive plasticity or ontogenetic drift? Plant Ecol. 201, 567-573. doi: 10.1007/s11258-008-9485-Z

Blindow, I., Dahlke, S., Dewart, A., Flügge, S., Hendreschke, M., Kerkow, A., et al. (2016). Long-term and interannual changes of submerged macrophytes and their associated diaspore reservoir in a shallow southern Baltic Sea bay: influence of eutrophication and climate. Hydrobiologia 778, 121-136. doi: 10. 1007/s10750-016-2655-4

Borenstein, M., Hedges, L. V., Higgins, J. P. T., and Rothstein, H. R. (2009). Introduction to Meta-Analysis. Chichester: John Wiley \& Sons. doi: 10.1002/ 9780470743386

Bunn, S. E., Davies, P. M., Kellaway, D. M., and Prosser, I. P. (1998). Influence of invasive macrophytes on channel morphology and hydrology in an open tropical lowland stream, and potential control by riparian shading. Freshw. Biol. 39, 171-178. doi: 10.1046/j.1365-2427.1998.00264.x

Burns, J. H., and Winn, A. A. (2006). A comparison of plastic responses to competition by invasive and non-invasive congeners in the Commelinaceae. Biol. Invasions 8, 797-807. doi: 10.1007/s10530-005-3838-5

Cahill, J. F. (2003). Lack of relationship between below-ground competition and allocation in 10 grassland species. J. Ecol. 91, 532-540. doi: 10.1046/j.1365-2745. 2003.00792.x

Carey, M. P., Sethi, S. A., Larsen, S. J., and Rich, C. F. (2016). A primer on potential impacts, management priorities, and future directions for Elodea spp. in high latitude systems: learning from the Alaskan experience. Hydrobiologia 777, 1-19. doi: 10.1007/s10750-016-2767-x

Carniatto, N., Thomaz, S. M., Cunha, E. R., Fugi, R., and Ota, R. R. (2013). Effects of an invasive alien Poaceae on aquatic macrophytes and fish communities in a neotropical reservoir. Biotropica 45, 747-754. doi: 10.1111/btp.12062

Chesson, P., and Kuang, J. J. (2008). The interaction between predation and competition. Nature 456, 235-238. doi: 10.1038/nature07248

Connell, J. H. (1983). On the prevalence and relative importance of interspecific competition: evidence from field experiments. Am. Nat. 122, 661-696. doi: $10.1086 / 284165$

Craine, J. M., and Dybzinski, R. (2013). Mechanisms of plant competition for nutrients, water and light. Funct. Ecol. 27, 833-840. doi: 10.1111/1365-2435. 12081

Cuassolo, F., Navarro, M. B., Balseiro, E., and Modenutti, B. (2016). Effect of light on particulate and dissolved organic matter production of native and exotic macrophyte species in Patagonia. Hydrobiologia 766, 29-42. doi: 10.1007/ s10750-015-2434-7

Daehler, C. C. (2003). Performance comparisons of co-occurring native and alien invasive plants: implications for Conservation and Restoration. Ann. Rev. Ecol. Evol. Syst. 34, 183-211. doi: 10.1146/annurev.ecolsys.34.011802. 132403

Daehler, C. C., and Strong, D. R. (1994). "Native plant biodiversity vs. the introduced invaders: status of the conflict and future management options," in Biological Diversity: Problems and Challenges, eds S. K. Majumdar, F. J. Brenner, J. E. Lovich, J. F. Schalles, and E. W. Miller (Easton, PA: Pennsylvania Academy of Science), 92-113.

Davis, M. A. (2009). Invasion Biology. Oxford: Oxford University Press.

Doyle, R. D., Francis, M. D., and Smart, R. M. (2003). Interference competition between Ludwigia repens and Hygrophila polysperma: two morphologically similar aquatic plant species. Aquat. Bot. 77, 223-234. doi: 10.1016/S03043770(03)00104-9

Engelhardt, K. A. M. (2011). “Aquatic eutrophication," in Encyclopedia of Biological Invasions, eds D. Simberloff and M. Rejmanek (London: University of California Press), 209-213.

Fasoli, J. V. B., Michelan, T. S., and Thomaz, S. M. (2015). Sediment composition mediates the invasibility of aquatic ecosystems by a non-native Poaceae species. Acta Limn. Bras. 27, 165-170. doi: 10.1590/S2179-975X5214

Fernandes, L. F. G., Teixeira, M. C., and Thomaz, S. M. (2013). Diversity and biomass of native macrophytes are negatively related to dominance of an invasive Poaceae in Brazilian sub-tropical streams. Acta Limn. Bras. 25, 202-209. doi: 10.1590/S2179-975X2013000200011

Fridley, J. D. (2011). "Invasibility, of communities and ecosystems," in Encyclopedia of Biological Invasions, eds D. Simberloff and M. Rejmánek (London: University of California Press), 356-360.

Gibson, D. J., Connolly, J., Hartnett, D. C., and Weidenhamer, J. D. (1999). Designs for greenhouse studies of interactions between plants. J. Ecol. 87, 1-16. doi: $10.1046 /$ j.1365-2745.1999.00321.x

Gibson, K. D., Fischer, A. J., and Foin, T. C. (2004). Compensatory responses of late watergrass (Echinochloa phyllopogon) and rice to resource limitations. Weed Sci. 52, 271-280. doi: 10.1614/WS-03-103R

Goldberg, D. E., and Scheiner, S. M. (2001). "ANOVA and ANCOVA: field competition experiments," in Design and analysis of Ecological Experiments, eds S. M. Scheiner and J. Gurevitch (New York, NY: Oxford University Press), 69-93.

Goldsborough, W. J., and Kemp, W. M. (1988). Light responses of a submersed macrophyte: implications for survival in turbid tidal waters. Ecology 69, 1775-1786. doi: 10.2307/1941156

Gomaa, N. H., and AbdElgawad, H. R. (2012). Phytotoxic effects of Echinochloa colona (L.) Link. (Poaceae) extracts on the germination and seedling growth of weeds. Span. J. Agric. Res. 10, 492-501. doi: 10.5424/sjar/2012102194-11

Gopal, B., and Goel, U. (1993). Competition and allelopathy in aquatic plant communities. Bot. Rev. 59, 155-210. doi: 10.1007/BF02856599

Grace, J. B. (1987). The impact of preemption on the zonation of two Typha species along lakeshores. Ecol. Monog. 57, 283-303. doi: 10.2307/2937088

Grime, J. P. (1979). Plant Strategies and Vegetation Processes. New York, NY: John Wiley and Sons.

Havel, J. E., Lee, C. E., and Zanden, M. J. V. (2005). Do reservoirs facilitate invasions into landscapes? Bioscience 55, 518-525. doi: 10.1641/00063568(2005)055[0518:DRFIIL]2.0.CO;2

Janeček, S., Patáèová, E., and Klimešová, J. (2014). Effects of fertilization and competition on plant biomass allocation and internal resources: does Plantago lanceolata follow the rules of economic theory? Folia Geobot. 49, 49-64. doi: 10.1007/s12224-013-9161-5

Jauni, M., and Ramula, S. (2015). Meta-analysis on the effects of exotic plants on the fitness of native plants. Perspect. Plant Ecol. Evol. Syst. 17, 412-420. doi: 10.1016/j.ppees.2015.06.002

Kiaer, L. P., Weisbach, A. N., and Weiner, J. (2013). Root and shoot competition: a meta-analysis. J. Ecol. 101, 1298-1312. doi: 10.1007/s00572-0110398-7

Leimu, R., and Koricheva, J. (2004). Cumulative meta-analysis: a new tool for detection of temporal trends and publication bias in ecology. Proc. R. Soc. B 271, 1961-1966. doi: 10.1098/rspb.2004.2828

Levine, J. M. (2008). Species diversity and biological invasions relating local process to community pattern. Science $288,852-854$. doi: $10.1126 /$ science.288.5467.852

Li, F., Li, Y., Qin, H., and Xie, Y. (2011). Plant distribution can be reflected by the different growth and morphological responses to water level and shade in two emergent macrophyte seedlings in the Sanjiang Plain. Aquat. Ecol. 45, 89-97. doi: 10.1007/s10452-010-9334-8

Madsen, J. D., Sutherland, J. W., Bloomfield, J. A., Eichler, L. W., and Boylen, C. W. (1991). The decline of native vegetation under dense Eurasian watermilfoil canopies. J. Aquat. Plant Manag. 29, 94-99.

Martin, G. D., and Coetzee, J. A. (2014). Competition between two aquatic macrophytes, Lagarosiphon major (Ridley) Moss (Hydrocharitaceae) and Myriophyllum spicatum Linnaeus (Haloragaceae) as influenced by substrate sediment and nutrients. Aquat. Bot. 114, 1-11. doi: 10.1016/j.aquabot.2013. 11.001 
Michelan, T. S., Thomaz, S. M., and Bini, L. M. (2013). Native macrophyte density and richness affect the invasiveness of a tropical Poaceae species. PLoS One 8:e60004. doi: 10.1371/journal.pone.0060004

Michelan, T. S., Thomaz, S. M., Carvalho, P., Rodrigues, R. B., and Silveira, M. J. (2010a). Regeneration and colonization of an invasive macrophyte grass in response to desiccation. Nat. Conserv. 8, 133-139. doi: 10.4322/natcon. 00802005

Michelan, T. S., Thomaz, S. M., Mormul, R. P., and Carvalho, P. (2010b). Effects of an exotic invasive macrophyte (tropical signalgrass) on native plant community composition, species richness and functional diversity. Freshw. Biol. 55, 1315-1326. doi: 10.1111/j.1365-2427.2009.02355.x

Moore, J. E., and Franklin, S. B. (2012). Water stress interacts with early arrival to influence interspecific and intraspecific priority competition: a test using a greenhouse study. J. Veg. Sci. 23, 647-656. doi: 10.1111/j.1654-1103.2012. 01388.x

Moore, J. E., Wolfe, J. D., and Franklin, S. B. (2014). Growth responses of different aged individuals of Xanthium strumarium L. in flooded conditions. J. Torrey Bot. Soc. 14, 72-79. doi: 10.3159/TORREY-D-13-00031.1

Moreira, S. N., Pott, A., Pott, V. J., and Damasceno-Junior, G. A. (2011). Structure of pond vegetation of a vereda in the Brazilian Cerrado. Rodriguésia 62, 721-729. doi: 10.1590/S2175-78602011000400002

Mugwedi, L. F., Goodall, J., Witkowski, E. T. F., and Byrne, M. J. (2015). The role of reproduction in Glyceria maxima invasion. Afr. J. Range Forage Sci. 32, 59-66. doi: 10.2989/10220119.2014.929177

Nunes, L. S. C., and Camargo, A. F. M. (2017). Do interspecific competition and salinity explain plant zonation in a tropical estuary? Hydrobiologia 812, 67-77. doi: 10.1007/s10750-016-2821-8

Paciullo, D. S. C., Campos, N. R., Gomide, C. A. M., Castro, C. R. T., Tavela, R. C., and Rossielo, R. O. P. (2008). Crescimento de capim-braquiária influenciado pelo grau de sombreamento e pela estação do ano. Pesqui. Agropecu. Bras. 43, 917-923. doi: 10.1590/S0100-204X2008000700017

Paciullo, D. S. C., Fernandes, P. B., Gomide, C. A. M., Castro, C. R. T., Sobrinho, F. S., and Carvalho, C. A. B. (2011). The growth dynamics in Brachiaria species according to nitrogen dose and shade. Rev. Bras. Zootecn. 40, 270-276. doi: 10.1590/S1516-35982011000200006

Pott, V. J., and Pott, A. (2000). Plantas Aquáticas do Pantanal. Brasília: Embrapa.

Pott, V. J., Pott, A., Lima, L. C. P., Moreira, S. N., and Oliveira, A. K. M. (2011). Aquatic macrophyte diversity of the Pantanal wetland and upper basin. Braz. J. Biol. 71, 255-263. doi: 10.1590/S1519-69842011000200004

Powell, K. I., Chase, J. M., and Knight, T. M. (2011). A synthesis of plant invasion effects on biodiversity across spatial scales. Am. J. Bot. 98, 539-548. doi: 10.3732/ ajb.1000402

Powell, K. I., Chase, J. M., and Knight, T. M. (2013). Invasive plants have scaledependent effects on diversity by altering species-area relationships. Science 339, 316-318. doi: 10.1126/science.1226817

Pyšek, P., Richardson, D. M., Pergl, J., Jarošík, V., Sixtová, Z., and Weber, E. (2008). Geographical and taxonomic biases in invasion ecology. Trends Ecol. Evol. 23, 237-244. doi: 10.1016/j.tree.2008.02.002

R Development Core Team (2014). R: A Language and Environment for Statistical Computing. Vienna: R Foundation for Statistical Computing.

Rejmánek, M. (2011). "Invasiveness," in Encyclopedia of Biological Invasions, eds D. Simberloff and M. Rejmánek (London: University of California Press), 379-385.

Richardson, J. D. M., and Pyšek, P. (2008). Fifty years of invasion ecology - the legacy of Charles Elton. Divers. Distrib. 14, 161-168. doi: 10.1111/j.1472-4642. 2007.00464.x
Richter, D., and Gross, E. M. (2013). Chara can out compete Myriophyllum under low phosphorus supply. Aquat. Sci. 75, 457-467. doi: 10.1007/s00027-0130292-9

Roberts, D. E., Church, A. G., and Cummins, S. P. (1999). Invasion of Egeria into the Hawkesbury-Nepean River, Australia. J. Aquat. Plant Manag. 37, 31-34.

Robinson, D., Davidson, H., Trinder, C., and Brooker, R. (2010). Root shoot growth responses during inter specific competition quantified using allometric modelling. Ann. Bot. 106, 921-926. doi: 10.1093/aob/ mcq186

Schiffers, K., Tielborger, K., Tietjen, B., and Jeltsch, F. (2011). Root plasticity buffers competition among plants: theory meets experimental data. Ecology 92, 610-620. doi: 10.1890/10-1086.1

Seabloom, E. W., Harpole, W. S., Reichman, O. J., and Tilman, D. (2003). Invasion Competitive dominance, and resource use by exotic and native California grassland species. Proc. Natl. Acad. Sci. U.S.A. 100, 13384-13389. doi: 10.1073/ pnas. 1835728100

Seabloom, E. W., and van der Valk, A. G. (2003). Plant diversity, composition, and invasion of restored and natural prairie pothole wetlands: implications for restoration. Wetlands 23, 1-12. doi: 10.1672/0277-5212(2003)023[0001: PDCAIO]2.0.CO;2

Strayer, D. L. (2010). Alien species in fresh waters: ecological effects, interactions with other stressors, and prospects for the future. Freshw. Biol. 55, 152-174. doi: 10.1111/j.1365-2427.2009.02380.x

Thomaz, S. M., and Michelan, T. S. (2011). Associations between a highly invasive species and native macrophytes differ across spatial scales. Biol. Invasions 13, 1881-1891. doi: 10.1007/s10530-011-0008-9

Wang, J. W., Yu, D., Xiong, W., and Han, Y. Q. (2008). Above and belowground competition between two submersed macrophytes. Hydrobiologia 607, 113-122. doi: 10.1007/s10750-008-9371-7

Wilson, S. D., and Keddy, P. A. (1991). Competition, survivorship and growth in macrophyte communities. Freshw. Biol. 25, 331-337. doi: 10.1111/j.1365-2427. 1991.tb00495.x

Witkowski, E. T. F. (1991). Growth and competition between seedlings of Protea repens (L.) L. and the alien invasive, Acacia saligna (Labill.) Wendl. in relation to nutrient availability. Funct. Ecol. 5, 101-110. doi: 10.2307/238 9560

Xu, K., Ye, W., Cao, H., Deng, X., Yang, Q., and Zhang, Y. (2004). The role of diversity and functional traits of species in community invasibility. Bot. Bull. Acad. Sin. 45, 149-157.

Zhu, J., Jiang, L., Zhang, Y., Jiang, Y., Tao, J., Tian, L., et al. (2015). Below ground competition drives the self-thinning process of Stipa purpurea populations in northern Tibet. J. Veg. Sci. 26, 166-174. doi: 10.1111/jvs.12207

Conflict of Interest Statement: The authors declare that the research was conducted in the absence of any commercial or financial relationships that could be construed as a potential conflict of interest.

Copyright (c) 2018 Michelan, Thomaz, Bando and Bini. This is an open-access article distributed under the terms of the Creative Commons Attribution License (CC BY). The use, distribution or reproduction in other forums is permitted, provided the original author(s) and the copyright owner(s) are credited and that the original publication in this journal is cited, in accordance with accepted academic practice. No use, distribution or reproduction is permitted which does not comply with these terms. 